\title{
Isothermal Amplification of Rabies Virus Gene
}

\author{
Makoto SUGIYAMA ${ }^{1)}$, Naoto ITO $^{1)}$ and Nobuyuki MINAMOTO ${ }^{1)}$ \\ ${ }^{1)}$ Laboratory of Zoonotic Diseases, Faculty of Agriculture, Gifu University, 1-1 Yanagido, Gifu 501-1193, Japan
}

(Received 7 March 2003/Accepted 16 June 2003)

ABSTRACT. A sensitive and specific in situ amplification technique is needed to elucidate the dynamics of rabies virus in the body during the long incubation period after infection. To overcome the disadvantage of using the traditional reverse transcription (RT)-PCR in in situ studies, an isothermal nucleic acid sequence-based amplification (NASBA) technique was developed for detection of the rabies vi rus gene. The NASBA technique involves the use of 4 enzymatic activities to produce multiple RNA copies of the target sequence by means of double-strand cDNA intermediates under an isothermal condition without thermocycling. The amplified cDNA intermediates from the genomic RNA in the rabies virion and the total RNA in the infected cells in NASBA reaction were analyzed by Southern hybridi zation assays. The specific amplified products of the rabies viral gene with the expected length were detected after $8 \mathrm{hr}$ of incubation in NASBA using both of the RNAs as templates. The NASBA system used in this study was less sensitive than the general RT-PCR technique. This may have been because we employed Southern hybridization for the amplified cDNA intermediates, not many RNA copies, to evaluate the NASBA results. In conclusion, we successfully amplified the rabies viral gene in the NASBA reaction under an is othermal condition. The unique character of this technique would make it particularly valuable for in situ studies not only on rabies virus but also on other RNA viruses.

KEY WORDS: isothermal amplification, NASBA, rabies virus, RT-PCR, Southern hybridization.

J. Vet. Med. Sci. 65(10): 1063-1068, 2003

Rabies virus causes a fatal neurological disease in all mammals, including humans. Rabies virus belongs to the Lyssavirus genus of the family Rhabdoviridae. The genome is an unsegmented negative-sense RNA of about $12 \mathrm{~kb}$, encoding five structural proteins: nucleoprotein $(\mathrm{N})$, phosphoprotein $(\mathrm{P})$, matrix protein, glycoprotein and large protein.

Rabies is probably the oldest recorded infection of mankind [5]. Humans and animals become infected with the rabies virus mainly by a bite from a rabid animal. The incubation period usually lasts several days to a few months, but periods of more than six years have been reported in exceptional cases [17]. A small number of rabies virus particles or viral genes is probably present in a living body during the incubation period. It is not clear what happens when the virus invades and replicates at the biting site and in the brain. This can only be determined by using a specific and sensitive method for detection of a single copy of the rabies gene in each cell. One of the most effective methods is in situ gene amplification [14]. In situ reverse transcription (RT)-PCR was developed for detection and localization of viral RNA in formalin-fixed tissue or cultured cells [1, 2, 13]. However, there have been problems such as destruction of cell morphology, high background, and diffusion of the amplified product [13]. It is thought that the high temperature required for thermocycling in PCR often causes cell damage, creation of diffused products, and prevention of accurate localization in fixed tissue or cells [14].

An alternative method to RT-PCR is nucleic acid sequence-based amplification (NASBA), which is based on transcription using three enzymes, reverse transcriptase, T7 RNA polymerase and $\mathrm{RNaseH}$, under an isothermal condition [3]. The NASBA technique has been successfully applied to the diagnosis of rabies [18]. Diagnosis of rabies by NASBA in clinical samples was performed using a commercially available electrochemiluminescence (ECL) system. It has also been used to detect a number of pathogens $[4,7,8,10-12,20]$. It has been reported that an in situ NASBA technique was useful for detecting viral RNA in measles-infected cell culture [9]. In this study, we focused on the development of an effective NASBA technique for amplification of the rabies virus gene in vitro prior to applying to in situ study.

\section{MATERIALS AND METHODS}

Cells and virus: BHK and CER [16] cells were maintained in Eagle's minimal essential medium supplemented with $10 \%$ tryptose phosphate broth and $5 \%$ fetal calf serum. BHK cells were used for preparation of a stock of the CVS$\mathrm{CE}$ strain of rabies virus. The CVS-CE strain was derived from the CVS strain after 84 passages in chick embryonic fibroblasts, as described previously [15].

Extraction of RNA: Genomic RNA of the CVS-CE strain was extracted from the stock virus using Isogen (Nippon Gene, Tokyo, Japan) and quantitated using a spectrophotometric method at a wavelength of $260 \mathrm{~nm}$. Total RNA was also extracted from CER cells infected with the CVS-CE strain using Isogen.

$P C R$ : To prepare template RHN29-T7 for NASBA, template TP8-10 for PCR, and probe RHN29 for Southern hybridization, the $\mathrm{N}$ gene was partially amplified by PCR with each pair of the primers using a plasmid containing the $\mathrm{N}$ gene of the RC-HL strain of rabies virus [6] (Fig. 1). These PCR products were purified in a low-melting-temperature agarose gel. PCR was also carried out to check the 
(A)

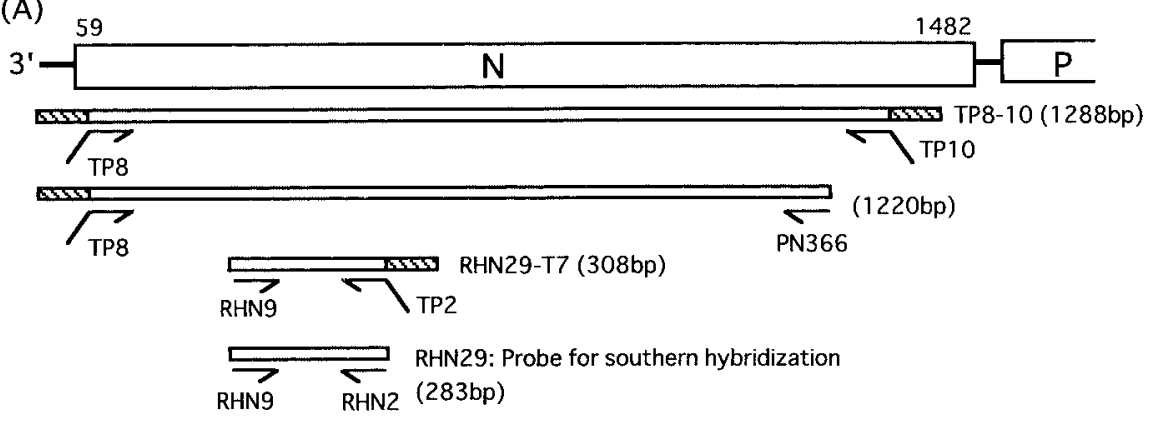

(B)

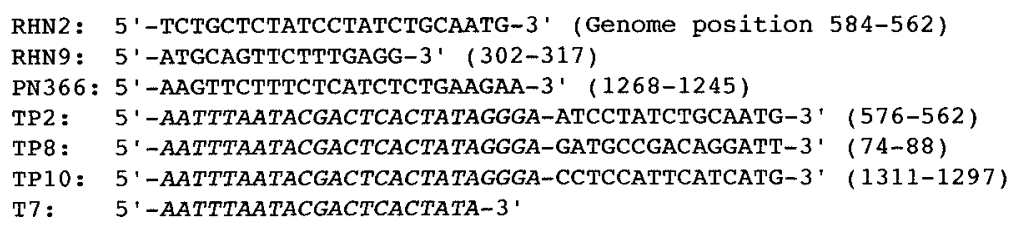

Fig. 1. A schematic representation of the positions (A) and sequences (B) of primers on the rabies $\mathrm{N}$ gene for NASBA and PCR. Italicized bases indicate a T7 promoter sequence.
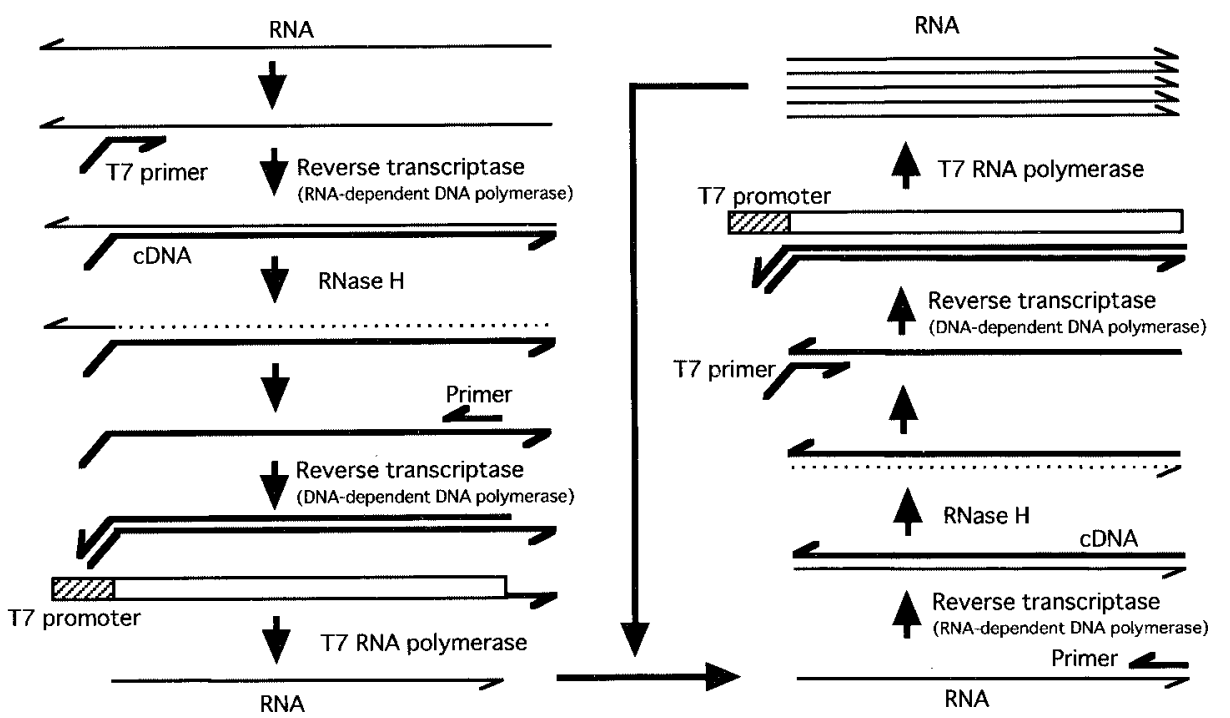

Fig. 2. Scheme for the amplification of RNA and cDNA by the NASBA reaction.

synthesis of single- or double-stranded cDNA in the NASBA system.

NASBA: The NASBA method was performed as described by Guatelli et al. [7] with some modifications. The principle of the NASBA reaction is shown in Fig. 2. Basically, the target gene was brought up to a 50- $\mu$ l final reaction volume containing $40 \mathrm{mM}$ Tris- $\mathrm{HCl}(\mathrm{pH} 8.0), 8$ $\mathrm{mM} \mathrm{MgCl} 2,25 \mathrm{mM} \mathrm{NaCl}$ (or $50 \mathrm{mM} \mathrm{KCl}$ ), $2 \mathrm{mM}$ spermidine hydrochloride, $5 \mathrm{mM}$ dithiothreitol, bovine serum albumin (BSA, $100 \mu \mathrm{g} / \mathrm{ml}$ ), $1 \mathrm{mM}$ (each) deoxyribonucleoside triphosphate, $2.5 \mathrm{mM}$ (each) ribonucleoside-5-triphosphate, 31.3 U of T7 RNA polymerase (Takara, Shiga, Japan), 11.3 $\mathrm{U}$ of reverse transcriptase RAV-2 (Takara, Shiga, Japan), and $4 \mu \mathrm{M}$ each of two primers. RAV-2 has enzymatic activ- ities of RNA- and DNA-dependent DNA polymerase and RNaseH. PCR product RHN29-T7, genomic RNA from the stock virus, or total RNA from virus-infected cells was used as a template in NASBA with each pair of the primers (Fig. 1). The reaction mixtures were incubated at $37^{\circ} \mathrm{C}$ for the times indicated, and the reactions were stopped by heating at $95^{\circ} \mathrm{C}$ for $5 \mathrm{~min}$.

Detection of amplification products: Amplification products were detected in Southern hybridization assays using an ECL direct nucleotide labeling and detection system (Amersham Biosciences, NJ, U.S.A.) as described previously [19]. The products were separated by $1.2 \%$ agarose gel electrophoresis and were transferred to a Hybond N+ nylon membrane (Amersham Biosciences, NJ, U.S.A.). The membrane 
was hybridized with probe RHN29 labeled with horseradish peroxidase. After Southern blot hybridization, the signal was detected using the ECL detection system.

\section{RESULTS}

Optimization of NASBA reaction: NASBA utilizes simultaneous reverse transcription and RNA transcription to produce multiple RNA copies of the target sequence by means of cDNA intermediates (Fig. 2). The double-stranded cDNAs from RNA are used to produce RNA copies. The target RNAs can further serve as templates for additional amplification of the target sequence. The synthesis of single- and double-stranded cDNAs in NASBA reaction with $25 \mathrm{mM} \mathrm{NaCl}$ or $50 \mathrm{mM} \mathrm{KCl}$ and with/without BSA $(100 \mu \mathrm{g} /$ $\mathrm{m} l$ ) was confirmed by PCR. After 90-min incubation at $37^{\circ} \mathrm{C}$ under different conditions in NASBA reaction with two primers, TP8 and TP10, and $900 \mathrm{ng}$ of rabies genomic RNA, PCRs with primers T7 and RHN2 and with T7 and RHN9 were carried out to confirm the presence of positivesense single- and double-stranded cDNAs, respectively (Fig. 3). In NASBA, positive-sense cDNA containing the T7 primer sequence at the 5' end is first synthesized by reverse transcriptase from negative-sense genomic RNA using TP8 and then negative-sense RNA is removed by RNaseH. This product can be amplified by PCR using primers $\mathrm{T} 7$ and RHN2, and the PCR product can be observed as a 536-bp band in agarose gel. As shown in Fig. 3 , a single DNA product of 536 bp was detected in NASBA reaction with both $\mathrm{NaCl}$ and $\mathrm{KCl}$ and with/without BSA. The negative-sense cDNA with the $\mathrm{T} 7$ primer sequence is subsequently synthesized from the positive-sense cDNA using TP10. This negative-sense cDNA can be amplified by PCR using T7 and RHN9, and the PCR product can be observed as a 1035-bp band in agarose gel. We found strong signals of $1035 \mathrm{bp}$ in NASBA-PCR reaction with BSA, a weak signal with $\mathrm{NaCl}$ and no $\mathrm{BSA}$, and no signal with $\mathrm{KCl}$ and no BSA. Since the results indicated that BSA was essential for synthesis of double-stranded cDNA, we decided to use NASBA reaction buffer containing $\mathrm{NaCl}$ and BSA.

NASBA reaction was carried out using $50 \mathrm{pg}$ of cDNA fragment RHN29-T7 as a template at $37^{\circ} \mathrm{C}$ for 2 to $6 \mathrm{hr}$. Those products were analyzed in Southern hybridization assays using probe RHN2-9 in the ECL system (Fig. 4). An intensified signal of $308 \mathrm{bp}$ was detected after $2 \mathrm{hr}$, and the signal was strongest after $8 \mathrm{hr}$. These intensified signals indicated the existence of DNA, not RNA, because those signals did not disappear following treatment with RNaseA (data not shown).

Amplification of rabies gene by NASBA: Genomic RNA extracted from the rabies virion was amplified by NASBA using primers TP8 and PN366. The NASBA reaction was carried out using $900 \mathrm{ng}$ of genomic RNA for $30 \mathrm{~min}$ to 22 hr. In Southern hybridization assays, a signal of approximately $720 \mathrm{bp}$ was observed after $2 \mathrm{hr}$, and the intensity of the signal increased with time (Fig. 5). The expected signal

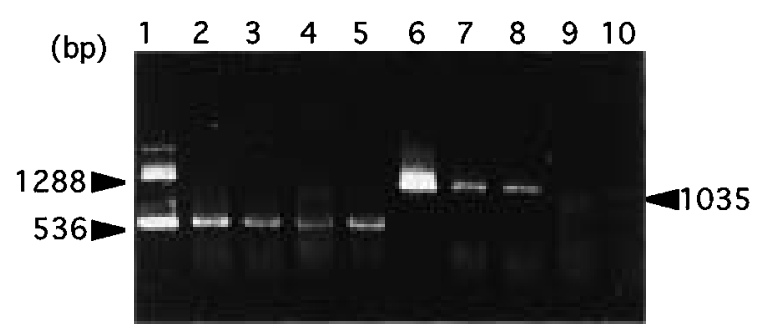

Fig. 3. Confirmation of positive-sense single- and doublestranded cDNA synthesized under different buffer conditions in the NASBA reaction. PCRs using the primer sets of T7 and RHN2 (lanes 1 to 5) and of T7 and RHN9 (lanes 6 to 10) were performed. Each NASBA product using the primer set of TP8 and TP10 in the general buffer (see Materials and Methods) with $50 \mathrm{mM} \mathrm{KCl}$ and BSA $(100 \mu \mathrm{g} / \mathrm{ml}$ ) (lanes 2 and 7), 25 $\mathrm{mM} \mathrm{NaCl}$ and BSA $(100 \mu \mathrm{g} / \mathrm{ml})$ (lanes 3 and 8$), 50 \mathrm{mM} \mathrm{KCl}$ (lanes 4 and 9), and $25 \mathrm{mM} \mathrm{NaCl}$ (lanes 5 and 10) was used for a template in PCR. The NASBA reaction was carried out at $37^{\circ} \mathrm{C}$ for $90 \mathrm{~min}$. The first cDNA product synthesized using primer TP8 from RNA could be amplified as DNA of $536 \mathrm{bp}$ by PCR using primers $\mathrm{T} 7$ and RHN2. The second product synthesized using primer TP10 from the first product could be amplified as DNAs of 1,035 bp and 1,288 bp by PCR using primers T7 and RHN2. The purified DNA fragment TP8-10 (lanes 1 and 6) was also used for a template of PCR as a control.

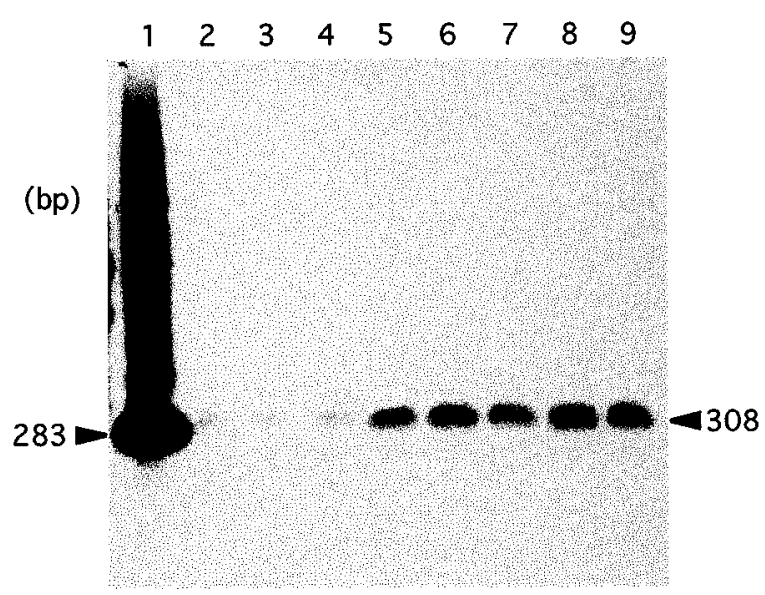

Fig. 4. Time course of amplification of cDNA of the rabies virus gene in NASBA reaction using the purified DNA fragment RHN29-T7 as a template. The NASBA was performed at $37^{\circ} \mathrm{C}$ for $0 \mathrm{~min}$ (lane 2), $30 \mathrm{~min}$ (lane 3), and 1 to $6 \mathrm{hr}$ (lanes 4 to 9). Each NASBA (lanes 2 to 9) and PCR product RHN29 (lane 1) was analyzed in Southern hybridization assays using probe RHN29 labeled with horseradish peroxidase.

of approximately $1,220 \mathrm{bp}$ appeared after $8 \mathrm{hr}$. A specific broad band of 720 to $1,220 \mathrm{bp}$ was detected at $22 \mathrm{hr}$. These NASBA products were not detected in agarose gel stained with ethidium bromide (data not shown).

Total RNAs from rabies- and mock-infected CER cells were amplified by NASBA using TP8 and PN366 with incubation times of 2, 8 and $24 \mathrm{hr}$. The same template RNA was also used for RT-PCR with the primers RHN2 and RHN9. 


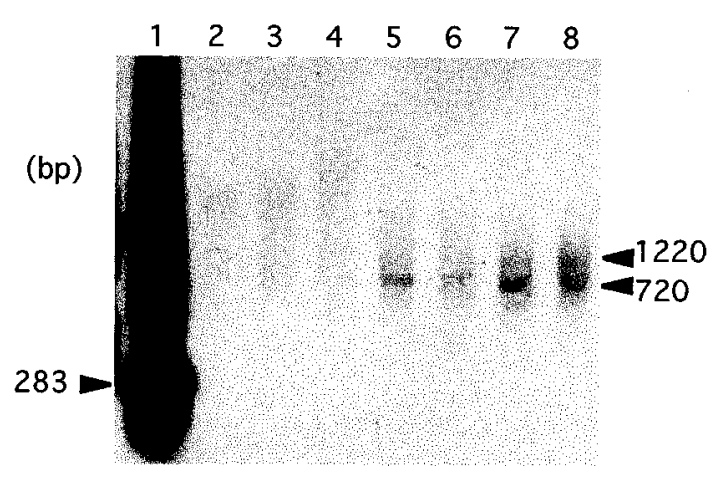

Fig. 5. Time course of amplification of cDNA of the rabies virus gene in NASBA reaction using genomic RNA from the virion as a template. The NASBA was performed at $37^{\circ} \mathrm{C}$ for 0 (lane 2), 0.5 (lane 3), 1 (lane 4), 2 (lane 5), 4 (lane 6), 8 (lane 7), and $22 \mathrm{hr}$ (lane 8). Each NASBA (lanes 2 to 9) and PCR product (lane 1) was analyzed in Southern hybridization assays using probe RHN29 labeled with horseradish peroxidase.

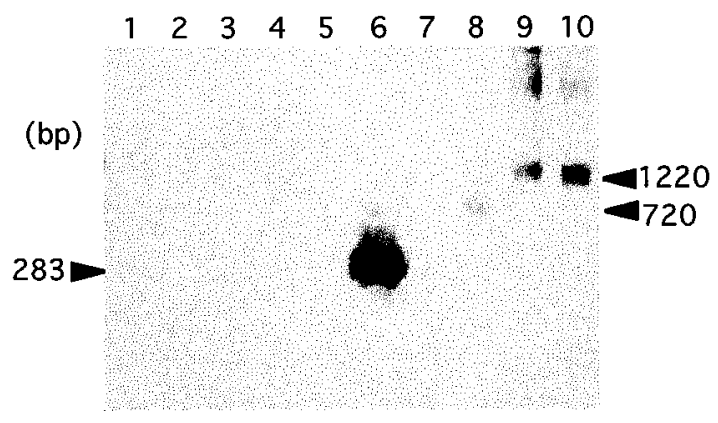

Fig. 6. Amplified cDNAs of the rabies virus gene in the NASBA reaction and PCR using total RNAs from mock(lanes 1 to 5) and rabies-infected (lanes 6 to 10) CER cells as templates. The NASBA was performed at $37^{\circ} \mathrm{C}$ for 0 (lanes 2 and 7), 2 (lanes 3 and 8), 8 (lanes 4 and 9), and 24 $\mathrm{hr}$ (lanes 5 and 10). PCR using primers RHN2 and RHN9 was performed. Each NASBA (lanes 2 to 5 and 7 to 10) and PCR product RHN29 (lanes 1 and 6) was analyzed in Southern hybridization assays using probe RHN29 labeled with horseradish peroxidase.

These amplified cDNAs from 1,500 $\mathrm{ng}$ of total RNA in NASBA and RT-PCR were analyzed by Southern hybridization (Fig. 6). A weak signal of about $720 \mathrm{bp}$ in length was detected after $2 \mathrm{hr}$ of incubation in the NASBA reaction using rabies-infected cellular RNA and disappeared after 8 $\mathrm{hr}$. The signals with expected length of $1,220 \mathrm{bp}$ by the NASBA reaction were observed at and after $8 \mathrm{hr}$ of incubation in rabies-infected CER cells. The signal intensity at 24 $\mathrm{hr}$ in NASBA was stronger than it at $8 \mathrm{hr}$. No signals were observed in NASBA and RT-PCR products using normal cellular RNA as a template by Southern hybridization analysis. The RT-PCR product with expected length of $283 \mathrm{bp}$ from rabies-infected cellular RNA was detected in both Southern hybridization assays and ethidium bromide-stain- ing gel, although the NASBA products were not directly detected at all in agarose gel (data not shown).

\section{DISCUSSION}

An in situ gene amplification technique is needed for the detection of a small number of rabies viral RNA in each cell during a long incubation period. The RT-PCR technique has been mainly used for amplification of the rabies virus gene. We propose a NASBA technique, an amplification approach that enables direct and isothermal amplification of viral RNA, as an alternative method to RT-PCR in in situ study. The relatively low isothermal temperature applied to NASBA allows it to be used for in situ amplification without disrupting the integrity of cells [3]. The NASBA technique was used in a previous study for rapid diagnosis of rabies [18]. However, since the diagnosis in that study requires use of a commercially available ECL kit, which contains standardized reagents for nucleic acid isolation, NASBA, and ECL detection, and automated reader, it is difficult to directly apply their system to in situ study. In the present study, we optimized the conditions of a NASBA reaction using rabies virus RNA prior to application to in situ study.

The amplification methodology involves the use of four enzymes, RNA-dependent DNA polymerase, RNaseH, DNA-dependent DNA polymerase and T7 RNA polymerase (Fig. 2). Two commercially available enzymes, T7 RNA polymerase and reverse transcriptase RAV-2, were used for NASBA in this study, because this reverse transcriptase has three enzymatic activities. Since there are differences in the compositions, $\mathrm{NaCl}, \mathrm{KCl}$ or $\mathrm{BSA}$, between the reaction buffer for each enzyme and the NASBA reaction buffer in the original report [7], different buffer conditions were tested to obtain double-stranded cDNA synthesized from the rabies viral genomic RNA. Negative-sense cDNA was synthesized only under the condition of the buffer containing BSA, while positive-sense cDNA from genomic rabies RNA was synthesized under all conditions (Fig. 3), suggesting that BSA is essential for the activity of RNaseH or DNA-dependent DNA polymerase in a NASBA reaction.

Under optimized conditions, double-stranded cDNA with a T7 promoter can produce RNA copies and subsequently proceed to the synthesis of new double-stranded cDNAs from their RNA copies in a NASBA reaction. In a preliminary test, the purified PCR product with a $\mathrm{T} 7$ promoter, RHN29-T7, was applied to the NASBA reaction as a template. The amplified double-stranded cDNA from RHN29T7 in the NASBA reaction was detected in a Southern hybridization assay as shown in Fig. 4. This result suggested that new RNA copies and subsequent products, new RHN29-T7, were synthesized from the template RHN29-T7 by multienzymatic activities under the condition described above. Taken together, these results indicate that rabies viral genomic RNA can produce double-stranded cDNA with a $\mathrm{T} 7$ promoter and subsequent positive-sense singlestranded RNA in the NASBA reaction under the conditions used in this study. 
A shorter-than-expected molecule of about 720 bp was detected after $2 \mathrm{hr}$ of incubation in the NASBA reaction using both rabies viral genomic RNA and total rabiesinfected cellular RNA as templates in Southern hybridization (Figs. 5 and 6). This molecule in NASBA using cellular RNA disappeared after $8 \mathrm{hr}$ of incubation. In contrast, the amount of the expected molecule of $1,220 \mathrm{bp}$ in length increased in the NASBA reaction using both RNAs after 8 hr. In the early stage of the reaction, double-stranded DNA with a T7 promoter that is shorter than the full-length DNA of 1,220 bp might be synthesized due to insufficient elongation of DNA by DNA polymerase and might produce the shorter-than-expected RNA and double-stranded DNA, although it is not clear why the length of the shorter DNA with T7 was $720 \mathrm{bp}$. The conversion of the shorter DNA into the full-length DNA might be due to sufficient elongation by DNA polymerase during the subsequent incubation. It has been reported that an amplified gene of less than 1,000 bp in size should be designed as a target for an effective NASBA reaction [3]. The insufficient elongation in this study may have been caused by the excessive length of a target gene. The design of a target gene of less than 1,000 bp may enable an amplified gene to be produced more effectively. These signals were thought to be specific for the rabies virus gene as well as for a previously reported amplified gene of hepatitis A virus in the NASBA reaction [11], because no signal was detected in normal CER cells.

Jean et al. [11] showed the superiority of the sensitivity of a NASBA system over RT-PCR for the amplification of viral target RNA. The NASBA system used in this study was much less sensitive than RT-PCR. A possible for this discrepancy in results is a difference in methods for analyzing NASBA results. For the analysis of NASBA products, Jean et al. employed Northern and dot hybridization methods for the amplified RNA, while we employed Southern hybridization for the amplified double-strand cDNA. It is thought that detection of the amplified RNA is needed to apply our system to diagnosis.

In summary, we successfully amplified the rabies viral gene in NASBA reaction under an isothermal condition. The unique character of this technique would make it particularly valuable for in situ study of low-level expression of rabies viral genes during the incubation period after infection. In addition, such a method could also be applied to the detection of other viral RNA genes.

ACKNOWLEDGMENT. This study was supported by a Grant-in-Aid for Scientific Research (no. 13556054) from the Ministry of Education, Science, and Culture, Japan.

\section{REFERENCES}

1. Alzahrani, A. J., Vallely, P. J. and McMahon, R. F. 2002. Development of a novel nested in situ PCR-ISH method for detection of hepatitis C virus RNA in liver tissue. J. Virol. Methods 99: 53-61.

2. Bagasra, O., Hauptman, S. P., Lischner, H. W., Sachs, M. and Pomerantz, R. J. 1992. Detection of human immunodeficiency virus type 1 provirus in mononuclear cells by in situ polymerase chain reaction. New Engl. J. Med. 326: 1385-1391.

3. Chan, A. B. and Fox, J. D. 1999. NASBA and other transcription-based amplification methods for research and diagnostic microbiology. Rev. Med. Microbiol. 10: 185-196.

4. Collins, R. A., Ko, L. S., So, K. L., Ellis, T., Lau, L. T. and Yu, A. C. 2002. Detection of highly pathogenic and low pathogenic avian influenza subtype H5 (Eurasian lineage) using NASBA. J. Virol. Methods 103: 213-225.

5. Fu, Z. F. 1997. Rabies and rabies research: past, present and future. Vaccine 15: S20-24.

6. Goto, H., Minamoto, N., Ito, H., Sugiyama, M., Kinjo, T., Mannen, K., Mifune, K. and Kawai, A. 1994. Nucleotide sequence of the nucleoprotein gene of the RC.HL strain of rabies virus, a seed strain used for animal vaccine production in Japan. Virus Genes 8: 91-97.

7. Guatelli, J. C., Whitfield, K. M., Kwoh, D. Y., Barringer, K. J., Richman, D. D. and Gingeras, T. R. 1990. Isothermal, in vitro amplification of nucleic acids by a multienzyme reaction modeled after retroviral replication. Proc. Natl. Acad. Sci. U. S. A. 87: 1874-1878.

8. Heim, A. and Schumann, J. 2002. Development and evaluation of a nucleic acid sequence based amplification (NASBA) protocol for the detection of enterovirus RNA in cerebrospinal fluid samples. J. Virol. Methods 103: 101-107.

9. Hofler, H., Putz, B., Mueller, J. D., Neubert, W., Sutter, G. and Gais, P. 1995. In situ amplification of measles virus RNA by the self-sustained sequence replication reaction. Lab. Invest. 73: $577-585$.

10. Jean, J., Blais, B., Darveau, A. and Fliss, I. 2002. Rapid detection of human rotavirus using colorimetric nucleic acid sequence-based amplification (NASBA)-enzyme-linked immunosorbent assay in sewage treatment effluent. FEMS Microbiol. Lett. 210: 143-147.

11. Jean, J., Blais, B., Darveau, A. and Fliss, I. 2001. Detection of hepatitis A virus by the nucleic acid sequence-based amplification technique and comparison with reverse transcription-PCR. Appl. Environ. Microbiol. 67: 5593-5600.

12. Lanciotti, R. S. and Kerst, A. J. 2001. Nucleic acid sequencebased amplification assays for rapid detection of West Nile and St. Louis encephalitis viruses. J. Clin. Microbiol. 39: 45064513.

13. Lau, G. K., Fang, J. W., Wu, P. C., Davis, G. L. and Lau, J. Y. 1994. Detection of hepatitis $C$ virus genome in formalin-fixed paraffin-embedded liver tissue by in situ reverse transcription polymerase chain reaction. J. Med. Virol. 44: 406-409.

14. Marshall, L. A. and Cubie, H. A. 1997. In situ gene amplification for virus detection. Rev. Med. Microbiol. 8: 157-169.

15. Minamoto, N., Ohta, S., Nakagawa, H., Kurata, K. and Sazawa, H. 1972. Propagation of fixed rabies virus in primary chick embryo fibroblasts. Ann. Rep. Natl. Vet. Assay Lab. 9: 89-91.

16. Smith, A. L., Tignor, G. H., Mifune, K. and Motohashi, T. 1997. Isolation and assay of rabies serogroup viruses in CER cells. Intervirology 8: 92-99.

17. Smith, J. S., Fishbein, D. B., Rupprecht, C. E. and Clark, K. 1991. Unexplained rabies in three immigrants in the United States. A virologic investigation. New Engl. J. Med. 324: 205211.

18. Wacharapluesadee, S. and Hemachudha, T. 2001. Nucleic-acid sequence based amplification in the rapid diagnosis of rabies. Lancet 358: 892-893.

19. Woodman, A. C., Sugiyama, M., Yoshida, K., Sugino, T., Bor- 
gya, A., Goodison, S., Matsumura, Y. and Tarin, D. 1996. Analysis of anomalous CD44 gene expression in human breast, bladder, and colon cancer and correlation of observed mRNA and protein isoforms. Am. J. Pathol. 149: 1519-1530.

20. Wu, S. J., Lee, E. M., Putvatana, R., Shurtliff, R. N., Porter, K.
R., Suharyono, W., Watts, D. M., King, C. C., Murphy, G. S., Hayes, C. G. and Romano, J. W. 2001. Detection of dengue viral RNA using a nucleic acid sequence-based amplification assay. J. Clin. Microbiol. 39: 2794-2798. 